\title{
Antioxidant Microemulsion-based Ethylene Vinyl Acetate Film Containing Mangiferin and Surfactants
}

\author{
Rungkan Boonnattakorn ${ }^{1,2, a,{ }^{*}}$, Amporn Sane ${ }^{1, b}$ and Vanee Chonhenchob ${ }^{1, \mathrm{c}}$ \\ ${ }^{1}$ Department of Packaging and Materials Technology, Kasetsart University, Bangkok 10900 Thailand \\ ${ }^{2}$ Department of Food Technology and Nutrition, Kasetsart University Chalermphrakiat Sakonnakhon \\ Province Campus, Sakonnakhon 47000 Thailand \\ arungkan.boo@ku.th , ${ }^{\mathrm{b}}$ amporn.s@ku.ac.th, ${ }^{\mathrm{c}}$ vanee.c@ku.ac.th
}

\begin{abstract}
Mangiferin, a natural antioxidant additive, was incorporated into an ethylene vinyl acetate copolymer (EVA) containing 18\% vinyl acetate (VA) using the emulsion solvent evaporation technique. Sorbitan ester $\left(\operatorname{Span}^{\mathbb{B}} 20\right)$ and polymeric surfactant (Pluronic $\left.{ }^{\mathbb{B}} \mathrm{P}-123\right)$ were compared. Mangiferin was finely dispersed in the suspension with the addition of surfactants studied. Span ${ }^{\mathbb{B}} 20$ was chosen as the surfactant for film preparation in the next step due to the dispersing and film forming properties. Effects of vinyl acetate (VA) contents on the film properties were investigated. The EVA films with $12 \%$ VA had the highest tensile strength and oxygen barrier, followed by 18, 25 and $40 \%$ VA, respectively. Addition of Span ${ }^{\mathbb{B}} 20$ had only a slight effect on mechanical and barrier properties of the films, but markedly increased the release of mangiferin from the EVA matrices except in the $40 \%$ VA films. The maximum concentrations of mangiferin released from the 40,25, 18 and $12 \%$ VA films into $95 \%$ ethanol were $83.30,66.84,51.77$ and $34.57 \mu \mathrm{g} . \mathrm{mL}^{-1}$, respectively. The release concentrations from the 40 and $25 \%$ VA films was 2.4 and 1.9 folds of that from the $12 \%$ VA film, respectively. The antioxidant activity of the EVA films containing mangiferin and $\operatorname{Span}^{\circledR} 20$ was $80 \%$ radical-scavenging capacity (RSC) for the 40 and $25 \% \mathrm{VA}$ and $60 \%$ RSC for the 18 and $12 \%$ VA. The release of mangiferin from the EVA matrices may be controlled by appropriate selection of the surfactants and vinyl acetate contents.
\end{abstract}

\section{Introduction}

Mangiferin is a xanthone derivative, abundant in several parts of mango (Mangifera indica) such as leaves, peels and barks [1]. Mangiferin has been reported to possess important pharmacological activity, including antioxidant, antiviral, antitumor, antiallergic, analgesic, anti-diabetic, antipyretic, immune modulatory, antibacterial and antifungal as reviewed by Singh et al. [2]. However, mangiferin has limited applications due to its poor solubility. Several efforts have been made to increase the solubility and bioavailability of mangiferin, for example an encapsulation of mangiferin in cyclodextrin derivatives $[3,4]$ and

* Corresponding author:rungkan.boo@ku.th 
microspheres of pectin calcium and chitosan [5]. Both techniques significantly increased mangiferin solubility.

A solid dispersion can also be used to improve the solubility of active substances by dispersing in inert carrier or polymer matrix in a form of micro-crystalline. Solid dispersion is not only applied for the improvement of the dissolution rate, but also used for controlled release of active substances. This technique has widely been used for drug delivery system for several benefits. To the authors' knowledge, solid dispersion has not been applied to food products. Therefore, this study was aimed at applying this technique to incorporate mangiferin in EVA copolymer that can be used for antioxidant materials.

A major challenge in incorporating antioxidants into polymers is solubility. Mangiferin poorly dissolves in EVA matrix. In order to avoid a separation of mangiferin from polymer, surfactant is added to improve dispersion and modifying interfacial bonding in a polymer composite. Since a surfactant consists of a hydrophilic part and a lipophilic part, it can locate at the interface of several active compounds and lower the surface tension. In this study, Sorbitan ester $\left(\operatorname{Span}^{\circledR} 20\right)$ and a triblock copolymer surfactant (Pluronic $\left.{ }^{\circledR} \mathrm{P}-123\right)$ were compared. The effect of VA content and surfactant on mechanical, barrier, thermal and antioxidant properties of the EVA films incorporated with mangiferin was investigated. The releasing profile of mangiferin from the films was also determined.

\section{Materials and Methods}

Materials. Mangiferin (96\% purity) was obtained from Changsha Huir Biological-Tech Co., Ltd., China. Ethylene vinyl acetate $(12,18,25,40 \%$ VA), Sorbitan monolaurate $\left(\operatorname{Span}^{\circledR} 20\right)$ and PEG-PPG-PEG (Pluronic ${ }^{\circledR} \mathrm{P}-123$ ) and 2,2- diphenyl-1-picrylhydrazyl (DPPH) were obtained from Sigma Aldrich. All reagents used in this study were of analytical grade.

Effect of Surfactant Types on Dispersing Performance and Film forming Properties. Mangiferin was dispersed in the EVA matrices using an emulsion solvent evaporation technique according to Rosca et al. [6] with a slight modification. Mangiferin emulsion was prepared by dissolving $1 \mathrm{~mL}$ of a surfactant $\left(\operatorname{Span}^{\mathbb{B}} 20\right.$ or Pluronic $\left.{ }^{\mathbb{B}} \mathrm{P}-123\right)$ in $8 \mathrm{~mL}$ toluene. One $\mathrm{mL}$ of mangiferin solution ( $10 \mathrm{mg} \mathrm{mL}^{-1}$ mangiferin in $50 \%$ tetrahydrofuran) was added to the mixture and homogenized for $1 \mathrm{~min}$ to obtain water-in-oil (W/O) emulsion. The emulsion was then added to EVA solution containing $5 \mathrm{mg} 18 \% \mathrm{VA}$ in $40 \mathrm{~mL}$ toluene and stirred for $10 \mathrm{~min}$. The film was prepared by pouring a polymer solution on a ceramic plate and the solvent was evaporated in a hot oven at $90^{\circ} \mathrm{C}$. Dispersing performance of magiferin in the EVA matrices was analyzed using a light microscope with a photo analysis (Primo star, United Kingdom). Imaging Software R 2.30 (Primo star, United Kingdom) was used for image processing.

Effect of VA Contents on the Properties of EVA Films Incorporated with Mangiferin. According to the results from the previous section, mangiferin-Span ${ }^{\mathbb{B}} 20$ emulsion was incorporated into the EVA solutions containing different vinyl acetate contents $(12,18,25$, and $40 \% \mathrm{VA})$. The film was prepared by pouring a polymer solution a ceramic plate and the solvent was evaporated in hot oven at $90^{\circ} \mathrm{C}$. The properties of the films were determined as described below.

Thermal Properties. The melting point $\left(T_{m}\right)$, heat of fusion and degree of crystallinity of the EVA films with varying VA contents $(12,18,25$ and 40) incorporated with mangiferin were analyzed using a differential scanning calorimeter (DSC model 883, Mettle Toledo, Ohio, USA). Approximately $20 \mathrm{mg}$ of a sample film was placed in an aluminum pan. The DSC was programmed to perform a heat-cool-heat from -80 to $160^{\circ} \mathrm{C}$ at a heating rate of $10^{\circ} \mathrm{C} \cdot \mathrm{min}^{-1}$. The glass transition temperature $\left(T_{g}\right)$ of the EVA films was analyzed by a modulated differential scanning calorimeter (MDSC). The amplitude of the temperature was 
$0.3^{\circ} \mathrm{C}$, the period was $50 \mathrm{~s}$ and the underlying heating rate was $2^{\circ} \mathrm{C} \min ^{-1}$. The samples were heated from -80 to $100^{\circ} \mathrm{C}$. DSC heating curves were analyzed using STARe software (Mettler Toledo Analytical Instruments).

Oxygen Permeability. The oxygen permeability of the films was determined using an oxygen permeation analyzer (model 8001, Illinois Instruments, Johnsburg, Illinois). A masking plate with a diameter of $5 \mathrm{~cm}$ was used. Antioxidant films $(\mathrm{n}=3)$ of $170 \pm 20 \mu \mathrm{m}$ thickness were measured for oxygen transmission rate (OTR).

Mechanical Properties. Tensile strength (TS) and elongation at break (EAB) were measured in accordance with the ASTM D 882 [7] using an Instron Testing machine (Model 4502, Instron Ltd., High Wycombe, Bucks, UK) with a $1 \mathrm{~kg}$ load cell. The initial grip separation was set at $50 \mathrm{~mm}$ and the crosshead speed was set at $1000 \mathrm{~mm} \mathrm{~s}^{-1}$. The film was cut into a $15 \mathrm{~mm} \times 100 \mathrm{~mm}$ strips. The experiments were done in 5 replicates.

Release Profile of Mangiferin from the EVA Matrices. Mangiferin released from the EVA matrix was determined as previously described by Boonnatakorn et al. [8]. Two-side liquid extraction method was used according to ASTM D 4754 [9]. Forteen pieces of a disk film were threaded onto a stainless steel wire with alternating glass bead spacers and placed in a glass vial, filled with $20 \mathrm{~mL}$ of $95 \%$ ethanol. Mangiferin was determined from the aliquots of the liquid sampled at various times using a UV-visible spectrophotometer (Libra S22, Biochrom Ltd, Cambridge, England) at $375 \mathrm{~nm}$. The concentrations were determined based on the standard curve of mangiferin at $25 \pm 2{ }^{\circ} \mathrm{C}$.

Antioxidant Activities of the EVA Films Incorporated with Mangiferin. The antioxidant properties of the films were determined using the 2,2- diphenyl-1-picrylhydrazyl (DPPH) free radical assay as described by Boonnatakorn et al. [8]. The stock solution of DPPH was prepared at the concentration of $2.4 \mathrm{mg} \mathrm{mL}^{-1}$ in ethanol. The reaction mixture consists of $0.6 \mathrm{~mL}$ ethanol containing mangiferin released from the EVA films in $3 \mathrm{~mL}$ DPPH working solutions. The mixture was kept in the dark for $20 \mathrm{~min}$ before the absorbance was measured at $515 \mathrm{~nm}$.

Statistical Analysis. The effect of VA content on thermal properties, mechanical properties, barrier properties of the mangiferin-EVA films were evaluated with analysis of variance (ANOVA). The mean value comparison was evaluated by Duncan's new multiple range test $(\mathrm{DMRT})$ at $\mathrm{p} \leq 0.05$.

\section{Results and Discussion}

Effect of Surfactant Types on Dispersing Performance and Film Forming Properties. Fig. 1 shows the optical microscopy image of the EVA films incorporated with mangiferin using different types of surfactants $\left(\operatorname{Span}^{\mathbb{B}} 20\right.$ and Pluronic $\left.{ }^{\mathbb{B}} \mathrm{P}-123\right)$ compared with that without surfactant. In the presence of surfactants, mangiferin particles were finely dispersed in the EVA films. Agglomeration of mangiferin particles was observed in the films without surfactant. The results indicate that the surfactants used in this study can prevent the mangiferin particles from agglomeration. Slight differences on dispersing and film forming properties were shown using different surfactants. The chemical structure of surfactants has the effect on micelle formation, particle size and particle distribution of active substances in the film matrices as well as the final properties of the films including film formation and thermal and mechanical properties. The sorbitan ester $\left(\operatorname{Span}^{\circledR} 20\right)$ and polymeric surfactant (Pluronic ${ }^{\mathbb{R}} \mathrm{P}-123$ ) used in this study differ in their structures and molecular weights. The sorbitan esters typically have low molecular weight and contains the hydrophilic heads and hydrophobic tails, while the polymeric surfactants have high molecular weight and contain several functional groups to interact with the particles. As shown in the results, the $\operatorname{Span}^{\mathbb{}} 20$ produced smaller particle sizes as compared to the Pluronic ${ }^{\circledR} \mathrm{P}-123$. This was probably due to the higher molecular weight of the triblock copolymer, Pluronic ${ }^{\circledR} \mathrm{P}-123(\mathrm{MW}=5,800)$ as 
compared to the soribitan ester, Span ${ }^{\circledR} 20$ containing $C_{12}$ alkyl group (MW = 346). High molecular weight polymer potentially interferes with binding of mangiferin on the hydrophilic micelle surface. Molecular weight of the surfactants also affects the dispersing performance of mangiferin in the latex. Short polymer chain allows the surfactant to freely transport in the continuous phase resulting in maximum performance as shown for the $\operatorname{Span}^{\mathbb{B}} 20$. Whereas the Pluronic ${ }^{\mathbb{B}} \mathrm{P}-123$ containing long polymer chain can be folded around the particles limiting the dispersing performance of mangiferin particles.

The droplet sizes as observed in the Pluronic ${ }^{\circledR} \mathrm{P}-123$ system $(82.88 \pm 30.05 \mu \mathrm{m})$ were higher than those in the $\operatorname{Span}^{\circledR} 20$ system $(39.86 \pm 20.71 \mu \mathrm{m})$ system. Size of emulsion droplets increased as the molecular weight of the surfactants as also reported by Fernandez and Jebbanema [10] that the polymer particle size increases with increasing the molecular weight of ethylene oxide surfactant. The hydrophilic-lipophilic balance (HLB) value is typically used in selecting the surfactants. The higher the HLB value, the more hydrophilic the surfactant, while the lower the HLB value, the more lipophilic the surfactant. We selected $\mathrm{Span}^{\circledR} 20($ HLB value $=8.6)$ and Pluronic ${ }^{\circledR} \mathrm{P}-123(\mathrm{HLB}$ value $=9)$ because their HLB values were appropriate for this system. According to the results, $\operatorname{Span}^{\circledR} 20$ was chosen to be used in the next section because it provided smaller droplet sizes and more stable microemulsion and the film with flexibility similar to the EVA film without surfactant. EVA film has widely been used for various packaging applications.
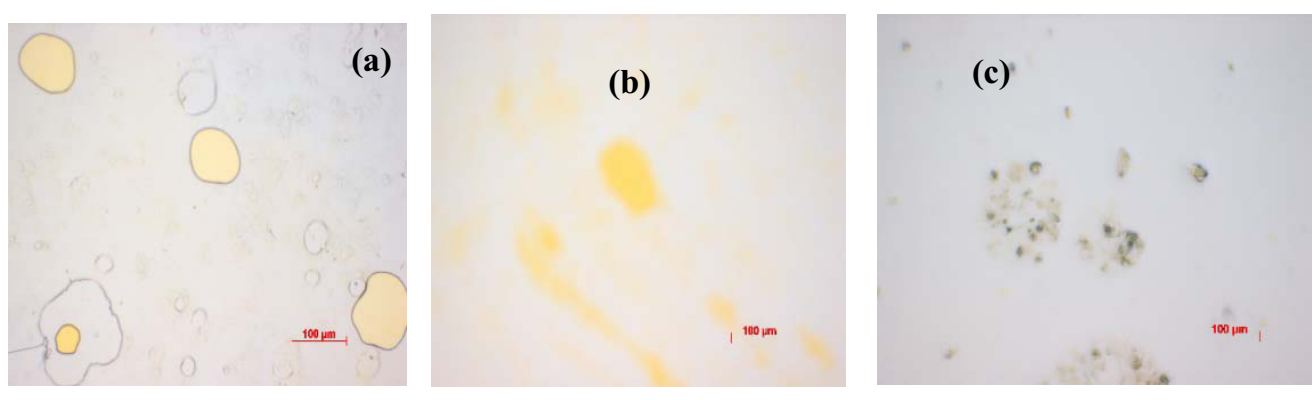

Figure 1. A 20x magnification image of mangiferin dispersing within EVA films containing 18\%VA (a) without surfactant, (b) with $\operatorname{Span}^{\mathbb{B}} 20$, and (c) with Pluronic ${ }^{\mathbb{B}} \mathrm{P}-123$

\section{Films Properties}

The properties the EVA films incorporated with mangiferin are presented in Table 1. VA content had a significant $(\mathrm{p} \leq 0.05)$ effect on film properties. Crystallinity increased with decreasing VA contents. Crystallinity is a primary factor affecting mechanical and barrier properties of the films. As shown in the results, the EVA films containing 12\% VA (highest crystallinity) had the highest tensile strength and Young's modulus and lowest elongation at break, followed by that of 18, 25 and 40\% VA, respectively. Flexibility increased with increasing VA contents. Barrier properties typically increased as crystallinity increased. The results showed that the lowest oxygen permeability (highest oxygen barrier) was observed in the EVA film with $12 \% \mathrm{VA}$, followed by that with 18,25 and $40 \% \mathrm{VA}$, respectively. The oxygen barrier property also plays an important role in preventing the oxidative reaction related to the antioxidant activity of the films. Thermal properties of the films, including glass transition temperature $\left(T_{g}\right)$ and melting temperature $\left(T_{m}\right)$ were also affected by VA content. $T_{m}$ decreased with increasing VA content as crystallinity decreased. With a higher degree of crystallinity, higher energy is required to break the crystal. VA content had a slight effect on $T_{g}$. The addition of Span ${ }^{\circledR} 20$ had only a slight effect on the film properties as 
compared to the EVA films incorporated with mangiferin without any surfactants as reported in our previous study [8]. The effect of surfactants on film flexibility was also reported by Dhaenens [11] that the sorbitan sesquioleate $\left(\operatorname{Span}^{\mathbb{B}} 83\right)$ increased flexibility of EVA40 and EVA28, but did not have the effect on EVA15 and EVA9, while changes in film flexibility were not observed when Tween 80 was added.

TABLE 1. THERMAL PROPERTIES, OXYGEN PERMEABILITY AND MECHANICAL PROPERTIES OF FILMS

\begin{tabular}{|c|c|c|c|c|}
\hline & \multicolumn{4}{|c|}{ Vinyl acetate content $[\% \mathrm{VA}]$} \\
\hline & 12 & 18 & 25 & 40 \\
\hline $\begin{array}{l}\text { Degree of } \\
\text { crystallinity }[\% X c]\end{array}$ & $17.63^{\mathrm{a}} \pm 0.31$ & $13.15^{\mathrm{b}} \pm 0.81$ & $12.98^{\mathrm{b}} \pm 0.32$ & $\begin{array}{c}11.00^{\mathrm{c}} \pm \\
0.56\end{array}$ \\
\hline Glass transition $\left[{ }^{\circ} \mathrm{C}\right]$ & $\begin{array}{c}-35.25^{\mathrm{a}} \pm \\
0.04\end{array}$ & $\begin{array}{c}-33.49^{\mathrm{ab}} \pm \\
0.98\end{array}$ & $\begin{array}{c}-34.26^{\mathrm{ab}} \pm \\
1.48\end{array}$ & $\begin{array}{c}-32.04^{\mathrm{b}} \pm \\
0.05\end{array}$ \\
\hline $\begin{array}{l}\text { Melting temperature } \\
{\left[{ }^{\circ} \mathrm{C}\right]}\end{array}$ & $\begin{array}{c}95.03^{\mathrm{a}} \pm \\
0.39\end{array}$ & $86.32^{\mathrm{b}} \pm 0.58$ & $79.09^{c} \pm 0.70$ & $\begin{array}{c}52.45^{\mathrm{d}} \pm \\
0.66\end{array}$ \\
\hline $\begin{array}{l}\text { Oxygen permeability } \\
\times 10^{-16}\left[\mathrm{~kg} \mathrm{~m} \mathrm{~m}^{2} \mathrm{~s}^{-1}\right. \\
\left.\mathrm{Pa}^{-1}\right]\end{array}$ & $0.80^{\mathrm{a}} \pm 0.25$ & $0.77^{\mathrm{a}} \pm 0.01$ & $1.10^{\mathrm{b}} \pm 0.08$ & $1.13^{\mathrm{b}} \pm 0.11$ \\
\hline $\begin{array}{l}\text { Tensile strength } \\
\text { [MPa] }\end{array}$ & $8.42^{\mathrm{a}} \pm 0.72$ & $7.37^{\mathrm{b}} \pm 0.64$ & $6.40^{\mathrm{b}} \pm 0.56$ & $2.01^{\mathrm{c}} \pm 0.14$ \\
\hline $\begin{array}{l}\text { Young's modulus } \\
\text { [MPa] }\end{array}$ & $\begin{array}{c}87.76^{\mathrm{a}} \pm \\
2.81\end{array}$ & $37.24^{\mathrm{b}} \pm 3.61$ & $12.00^{\mathrm{c}} \pm 0.75$ & $0.63^{\mathrm{d}} \pm 0.11$ \\
\hline $\begin{array}{l}\text { Elongation at } \\
\text { break[mm] }\end{array}$ & $\begin{array}{c}188.15^{\mathrm{a}} \pm \\
56.04\end{array}$ & $\begin{array}{l}375.29^{b} \\
\pm 23.45\end{array}$ & $\begin{array}{c}437.35^{b} \pm \\
32.98\end{array}$ & $>500$ \\
\hline
\end{tabular}

* Different letters in each row are significantly different by DMRT $(\mathrm{p} \leq 0.05)$.

\section{Release Profile of Mangiferin and the Antioxidant Activity of EVA Films}

Fig. 2 shows the release profile of mangiferin from the EVA matrix with different VA contents in the presence of $\operatorname{Span}^{\circledR} 20$. The concentration of mangiferin extracted from $95 \%$ ethanol was plotted against time. The highest concentration of mangiferin was released from the films containing $40 \% \mathrm{VA}$, followed by that with 25,18 and $12 \% \mathrm{VA}$, respectively. This was also due to the crystallinity effects. Crystallinity hinders the release of active substances from the polymer matrix which is related to free volume in the polymer. Mangiferin was released faster in the first $8 \mathrm{~h}$ and the equilibrium was reached after about $24 \mathrm{~h}$ in all systems. The maximum concentrations of mangiferin released into $95 \%$ ethanol were $83.30,66.84$, 51.77 and $34.57 \mu \mathrm{g} \mathrm{mL}^{-1}$ in $40,25,18$ and $12 \%$ VA films, respectively. It was noticed that the release concentrations from the 40 and 25\% EVA films were about 2.4 and 1.9 times of that from the $12 \%$ VA film, respectively. In our previous study [8], the release concentrations of mangiferin from the EVA films without any surfactants were much lower for the films with 12,18 and $25 \%$ VA content $\left(5-20 \mu \mathrm{g} \mathrm{mL}^{-1}\right)$. However, the release concentrations from the $40 \%$ VA film in both studies were in the same range. Results from the present study showed the effects of $\operatorname{Span}^{\circledR} 20$ on increasing the release rate of mangiferin from the EVA 
matrices as the equilibrium was reached after about $48 \mathrm{~h}$ in the EVA film without $\operatorname{Span}^{\circledR} 20$ as compared to $24 \mathrm{~h}$ in the film with $\mathrm{Span}^{\circledR} 20$. Other studies also reported that surfactants increased the release rate of active substances from the polymer matrices. For example, sorbitan sesquioleate $\left(\operatorname{Span}^{\circledR} 83\right)$ increased the release of metoprolol tartrate from the EVA containing 40\% VA [11] and poly(ethylene)-block-poly(ethylene glycol) (PE-PEG) increased the release of tocopherol from the polypropylene matrix [12].

The antioxidant activity of the EVA films incorporated with mangiferin was determined at various times as shown in Fig. 2. The line plot corresponding to the right y-axis showed the percentage of radical-scavenging capacity (\% RSC) of the EVA films with varying VA contents in the presence of $\operatorname{Span}^{\mathbb{B}} 20$. The highest antioxidant activity was observed in the EVA films with 40 and $25 \% \mathrm{VA}$, while the lowest antioxidant activity was found in the films with 18 and $12 \% \mathrm{VA}$. The maximum percentage of RSC of the 40, 25, 18 and 12\% EVA films incorporated with mangiferin in the presence of $\operatorname{Span}^{\circledR} 20$ were $81.97,77.05,68.73$ and 63.13, respectively. The results indicated that the percentage of RSC was related to the mangiferin released from the polymer matrices within specific ranges. The mangiferin concentrations in the range of about $60-80 \mu \mathrm{g} \mathrm{ml}^{-1}$ corresponded to the maximum of $80 \%$ $\mathrm{RSC}$ as shown in the 40 and 25\% VA films. Mangiferin concentrations in the range of about $30-50 \mu \mathrm{g} \mathrm{ml}^{-1}$ as for the 18 and $12 \% \mathrm{VA}$ films resulted in the maximum of $60 \% \mathrm{RSC}$. As compared to the results from our previous study [8], the maximum percentage of RSC of the EVA films incorporated with mangiferin without surfactant containing 40, 25, 18 and 12\% VA content were 81.90, 50.47, 37.27 and 21.93, respectively. The results suggested that addition of surfactant $\left(\operatorname{Span}^{\circledR} 20\right)$ significantly increased the antioxidant activity of about 2.9 folds in the 12\% VA films and 1.5 and 1.8 folds in 18 and $25 \%$ VA films, respectively. However, there was no effect on the $40 \%$ VA, which had the lowest crystallinity (11\%).

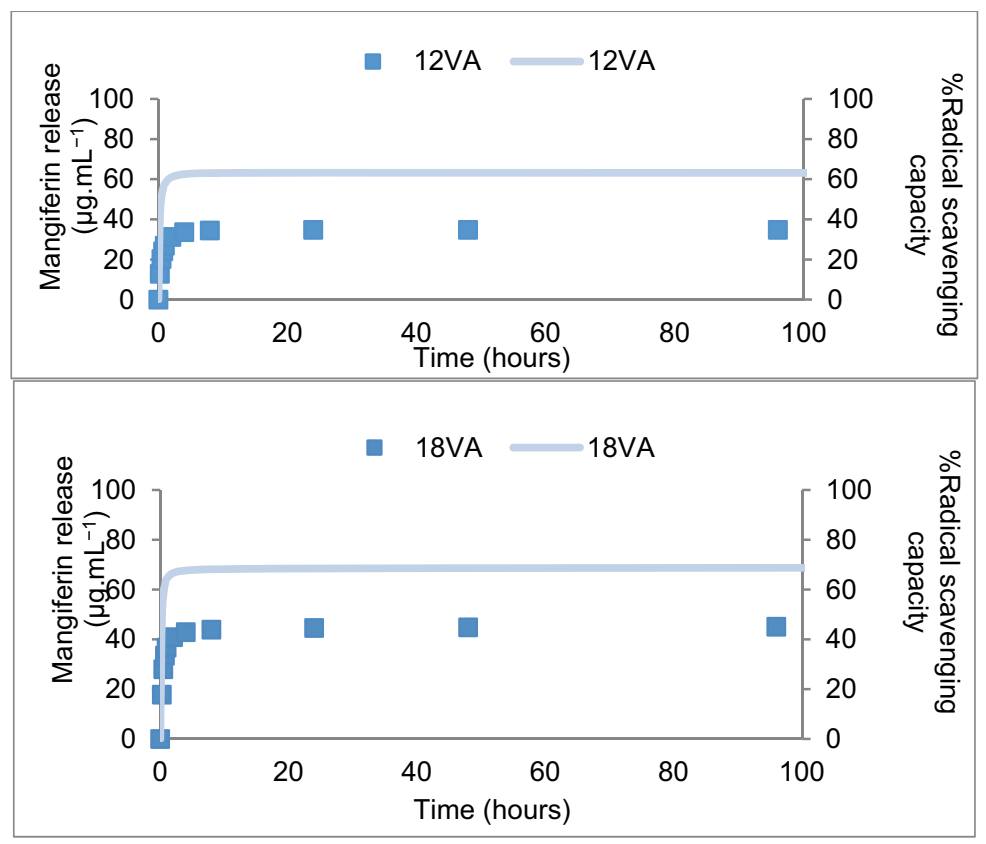




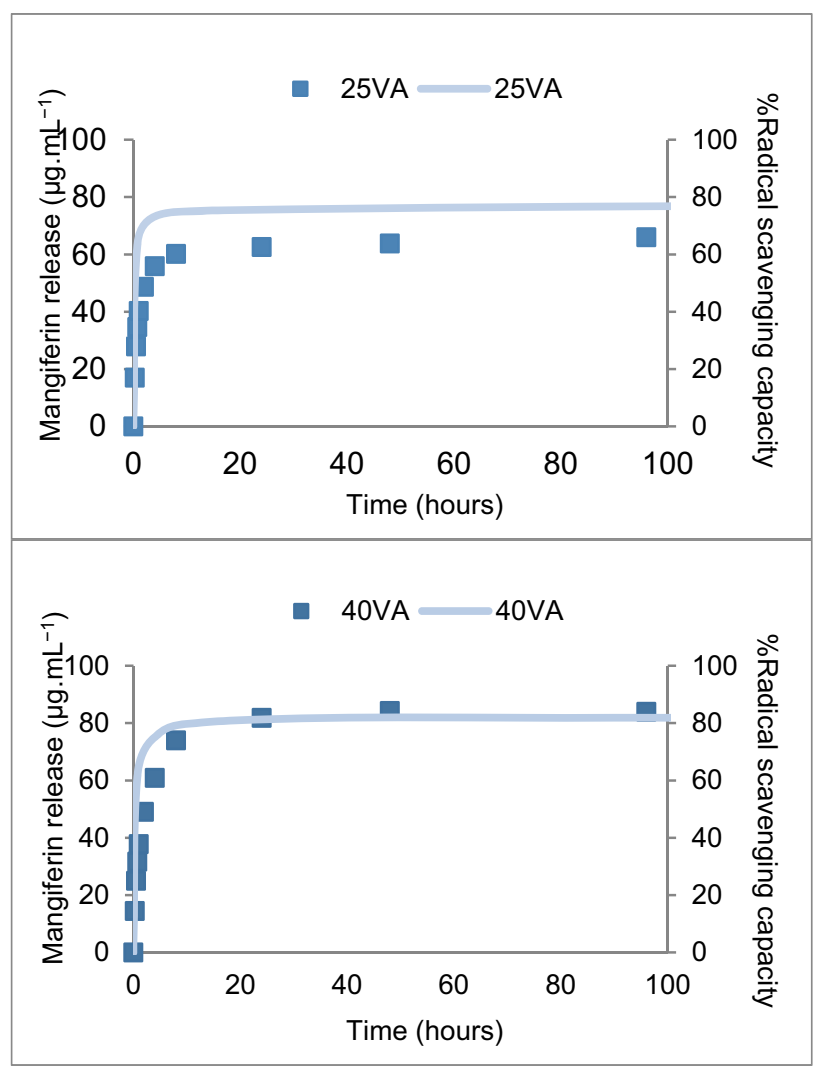

Figure 2. Plot symbols against time represent mangiferin release from EVA matrices in $95 \%$ ethanol (left y-axis). Plot lines against time represent remaining antioxidant activity in EVA films after released (right y-axis). All experiments were conducted at $25^{\circ} \mathrm{C}$.

\section{Conclusion}

Mangiferin could be incorporated into the EVA matrices using the emulsion solvent evaporation technique with the addition of appropriated surfactants. Mangiferin was finely dispersed in the EVA films in the presence of $\operatorname{Span}^{\circledR} 20$. Dispersing performance depends on the polar head, molecular weight and HLB value of the surfactants. Span ${ }^{\circledR} 20$ was chosen as it gave the good film forming property and flexibility. Mangiferin released into $95 \%$ ethanol at equilibrium were $83.30,66.84,51.77$ and $34.57 \mu \mathrm{g} \mathrm{mL}^{-1}$ for the $40,25,18$ and $12 \% \mathrm{VA}$ films, respectively. The antioxidant properties of the films were related to the release of mangiferin from the films. The $80 \%$ RSC was achieved from the 40 and $25 \%$ VA films, while the $60 \%$ RSC was achieved from the 18 and $12 \%$ VA, respectively. Varying degree of crystallinity with the addition of appropriate surfactants could potentially be used for controlling the release of active substances from the polymer matrices.

\section{Acknowledgements}

This research was partially funded by the Center for Advanced Studies in Agriculture and Food, Institute for Advanced Studies, Kasetsart University. 


\section{References}

1. M.T. Fernández-Ponce, L. Casas, M. Casimiro, M. Rodríquez, E. M. de la Ossa, Extraction of antioxidant compounds from different varieties of Mangifera indica leaves using green technologies, J. of Supercritical Fluids. 72 (2012) 168-175.

2. S.K. Singh, V.K. Sharm, Y. Kumar, S.S. Kumar, S.K. Sinha, Phytochemical and pharmacological investigations on mangiferin. Kerla Polonica. 55 (2009) 126-139.

3. Z. Wang, J. Deng, X. Li, Q. Wang, Dissoluble mangiferin inclusion compound and its preparation method. Chinese Patent CN101019877-A. (2007)

4. F.R. Ferreira, I.B. Valentim, E.L.C. Ramones, M.T.S. Trevisan, C. Olea-Azar, F. Perez-Cruz, F.C. de Abreu, M.O.F. Goulart, Antioxidant activity of the mangiferin inclusion complex with $\beta$-cyclodextrin. LWT-Food Science and Technology. 51 (2013) 129-134.

5. J.R.R. de Souza, J.I.X. de Carvalho, M.T.S. Trevisan, R.C.M. de Paula, N.M.P.S. Ricardo, J.P.A. Feitosa, Chitosan-coated pectin beads: Characterization and in vitro release of mangiferin. Food hydrocolloids. 23 (2009) 2278-2286.

6. I.D. Rosca, F. Watari, M. Uo, Microparticle formation and its mechanism in single and double emulsion solvent evaporation. J. of Controlled Release. 99 (2004) 271-280.

7. ASTM Standard D 882-02, Test method for tensile properties of thin plastic sheeting. ASTM International, West Conshohocken, PA. 2002.

8. R. Boonnatakorn, V. Chonhenchob, M. Siddiq, S.P. Singh, Controlled release of mangiferin using ethylene vinyl acetate matrix for antioxidant packaging. Packag. Technol. Sci. 28 (2014) 241-252.

9. ASTM Standard D 4754-98, Test method for two-sided liquid extraction of plastic materials using FDA migration cell. ASTM International, West Conshohocken, PA. 2003.

10. A.M. Fernandez, L. Jebbanema, The effect of surfactant selection on emulsion polymer properties. Information on http://www.pcimag.com

11. P.K. Dhaenens, Ethylene vinyl acetate as matrix for oral sustained release multiple-unit dosage forms produced via hot-melt extrusion. M.S. thesis, Ghent University, Belgium, 2010.

12. M.M. Castro-López, M.S. Dopico-García, A.A. Pernas, J.M. López-Vilariño, M.V. González-Rodríquez, Effect of PPG-PEG-PPG on the tocopherol-controlled release from films intended for food-packaging applications. J. Agric. Food Chem. 60 (2012) 8163-8170. 